\title{
HIF-1 signaling pathway involving iNOS, COX-2 and caspase-9 mediates the neuroprotection provided by erythropoietin in the retina of chronic ocular hypertension rats
}

\author{
DONGMEI GUI ${ }^{1}$, YANFENG LI $^{2}$, XIAOLONG CHEN ${ }^{1}$, DIANWEN GAO ${ }^{1}$, YANG YANG $^{1}$ and XUN LI ${ }^{1}$ \\ ${ }^{1}$ Department of Ophthalmology, Shengjing Hospital of China Medical University, Shenyang, Liaoning 110004; \\ ${ }^{2}$ Department of Neurosurgery, The People's Hospital of Liaoning Province, Shenyang, Liaoning 110025, P.R. China
}

Received March 25, 2014; Accepted August 22, 2014

DOI: $10.3892 / \mathrm{mmr} .2014 .2859$

\begin{abstract}
This study aimed to investigate the impacts of erythropoietin (EPO) on the electroretinogram b-wave (ERG-b), and on the mRNA and protein expression levels of hypoxia-inducible factor- $1 \alpha$ (HIF- $1 \alpha$ ), inducible nitric oxide synthase (iNOS), cyclooxygenase-2 (COX-2) and caspase-9 in chronic ocular hypertension rats. Episcleral vein cauterization (EVC) was used to establish the chronic ocular hypertension rat model based on the intraocular pressure (IOP) value. ERG-b and mRNA and protein expression levels of HIF-1 $\alpha$, iNOS, COX-2 and caspase-9 in normal, EVC-treated and EVC combined with EPO (EVC+EPO)-treated rats were measured by electroretinography, RT-PCR and western blotting, respectively. Moreover, the correlations of HIF-1 $\alpha$ with IOP, ERG-b, iNOS, COX-2 and caspase- 9 were evaluated. The mRNA and protein expression levels of HIF-1 $\alpha$, iNOS, COX-2 and caspase-9 in EVC-treated rats were increased significantly compared with normal rats. The peak expression levels of HIF-1 $\alpha$, iNOS, COX-2 and caspase-9 were respectively obtained 7, 7, 7 and 14 days postoperatively. Compared with EVC-treated rats, EPO administration weakened the mRNA and protein expression levels of HIF-1 $\alpha$, iNOS, COX-2 and caspase-9. The mRNA expression level of HIF-1 $\alpha$ demonstrated a significant positive correlation with IOP and ERG-b. HIF-1 $\alpha$ was positively correlated with iNOS, COX-2 and caspase- 9 at the mRNA and protein levels. The protective effect of EPO on the retina of chronic ocular hypertension rats may be mediated by the HIF-1 signaling pathway involving iNOS, COX-2 and caspase-9.
\end{abstract}

Correspondence to: Dr Dongmei Gui, Department of Ophthalmology, Shengjing Hospital of China Medical University, 36 Sanhao Street, Heping, Shenyang, Liaoning 110004, P.R. China E-mail: guidongmeigdm@hotmail.com

Key words: cyclooxygenase-2, caspase-9, hypoxia-inducible factor- $1 \alpha$, erythropoietin, glaucoma

\section{Introduction}

The ocular disorder of glaucoma, characterized by the progressive loss of retinal ganglion cells and their axons, accompanied by gradual loss of the visual field, is a leading cause of blindness, estimated to affect 79.6 million people worldwide by 2020 (1). Dysregulation of the blood flow with subsequent hypoxia has been suggested to be a mechanism of retinal damage in glaucoma (2). Hypoxia-inducible factor 1 (HIF-1) is a transcriptional activator that functions as a master regulator of oxygen homeostasis and plays an essential role in mammalian development, physiology and disease pathogenesis (3). HIF-1 is a heterodimer composed of the inducible expressed HIF-1 $\alpha$ subunit and the constitutively expressed HIF-1 $\beta$ subunit $(3,4)$. HIF-1 $\alpha$ expression is induced in hypoxic cells with an exponential increase in expression as cells are exposed to an oxygen concentration of $<6 \%$ (5). Previous studies have reported that the activation of the hypoxia-responsive transcription factor HIF-1 $\alpha$ is involved in the pathophysiology of glaucoma $(6,7)$. Moreover, a number of HIF-1 $\alpha$ targeted genes have also been investigated in retinas with glaucoma, including EPO, FLT-1, HSP-27, PAI-1, VEGF-A, ET-1, IGF2 and TGF 33 (7,8).

Our previous study investigated the expression levels of HIF-1 $\alpha$ and inducible nitric oxide synthase (iNOS), and the effect of erythropoietin (EPO) on the HIF-1\iNOS signal transduction pathway in the retina of chronic ocular hypertension rats (9). EPO is capable of protecting retinal ganglion cells from degeneration induced by acute ischemia-reperfusion injury, axotomy injury and light- and genetic-induced degeneration, and promoting the survival of retinal ganglion cells in DBA/2J glaucoma mice (10). Significant advances have been made in understanding the molecular pathology of glaucoma, particularly through the development of rat models of experimental glaucoma and the characterization of a spontaneous secondary form of glaucoma in DBA/2 substrains of inbred mice (2). However, the correlation between HIF-1 $\alpha$ and its targeted genes remains unclear and an investigation into EPO in glaucoma is warranted.

Cyclooxygenase-2 (COX-2) has been identified in the cornea, iris, ciliary body and various cell types within the neurosensory retina. The expression of the COX-2 enzyme in the ocular tissues plays a functional role for its pros- 
tanoid products (11). It has been reported that HIF-1 is an essential regulator of COX-2 induction in hypoxic monkey choroidal retinal endothelial cells (12). HIF-1 $\alpha$ has been reported to promote apoptosis, since caspase- 9 promoter contained HIF-1-binding elements and caspase-9 transcription could be induced by a hypoxic episode $(13,14)$. Activation of caspase- 9 has been identified in a rat model of experimental glaucoma (15). In the present study, chronic ocular hypertension rats were induced with episcleral vein cauterization (EVC). The mRNA and protein expression levels of HIF-1 $\alpha$, iNOS, COX-2 and caspase-9 were investigated in normal, EVC-treated, and EVC combined with EPO (EVC+EPO)-treated rats. In addition, the correlation of HIF-1 $\alpha$ with intraocular pressure (IOP), electroretinogram b-wave (ERG-b), iNOS, COX-2 and caspase-9 was also studied.

\section{Subjects and methods}

Animals. A total of 120 male Wistar rats (age, 40-50 days; weight, 200-250 g) without eye disease were obtained from the Experimental Animal Center of China Medical University, Shenyang, China. All rats were housed in a specific pathogen-free facility. The rats were randomly divided into 12 groups: One blank group; one group with rats injected with EPO and without ocular hypertension; five groups with rats under ocular hypertension for 3, 7, 14, 21 and 28 days, respectively; and five groups with rats injected with EPO and under ocular hypertension for 3, 7, 14, 21 and 28 days, respectively. The right eyes of rats in each group were selected as the experimental eyes to receive treatments and the left eyes were used as controls. The study was approved by the Animal Ethics Committee of Shengjing Hospital Affiliated to China Medical University.

Model establishment and sample preparation. Chronic ocular hypertension rats were induced with EVC as described previously (9). Two or three of the episcleral veins were coagulated by heat cure hemostat in the experimental group, while nothing was done to the veins in the blank group. A Tono-Pen II tonometer (Mentor Opthalmics, Inc., Norwell, MA, USA) was used to measure the IOP of the Wistar rats prior to surgery, half an hour after surgery and 3, 7, 14, 21 and 28 days after surgery. The postoperative IOP was $40 \%$ higher than that prior to surgery, indicating that the chronic ocular hypertension model was established successfully. This model closely mimics the natural disease process in certain forms of secondary glaucoma, and is one of the most commonly used models in rats (16). The rats were sacrificed in each group following the correct treatment. The entire retina was separated and stored as described previously for subsequent experiments (9).

Drug administration and ERG-b detection. Recombinant human EPO was purchased from Shenyang Sunshine Pharmaceutical Co., Ltd. (China). Wistar rats in the drug group were intraperitoneally injected with EPO $(5,000 \mathrm{U} / \mathrm{kg})$ 1 day before surgery, and 2, 6, 13, 20 and 27 days after surgery. The change in ERG-b was detected by VETS-3 electrophysiolography as described previously (9).
Measurement of $m R N A$ expression levels by semi-quantitative $R T-P C R$. First, total RNA from normal and glaucomatous whole retinas from each group was reverse transcribed into cDNA using random primers and SuperScript ${ }^{\mathrm{TM}}$ II RT (Invitrogen, Carlsbad, CA, USA). The target levels in each retina were normalized with the housekeeping gene glyceraldehyde-3-phosphate dehydrogenase (GAPDH) or $\beta$-actin. The sequences of the PCR primers and the product length of target genes (HIF-1 $\alpha$, iNOS, COX-2 and caspase-9) are listed in Table I. The PCR conditions and the electrophoresis and gel imaging processes were as described in our previous study (9). Briefly, PCR was performed in a $25 \mu \mathrm{l}$ reaction volume: $2.5 \mu \mathrm{l}$ cDNA, $2.5 \mu 1$ 10X PCR buffer (Takara Shuzo, Shiga, Japan), $2.0 \mu \mathrm{l}$ dNTP (2.5 mM; Takara Shuzo), $1.0 \mu \mathrm{l}$ of each primer $(100 \mathrm{pm} / \mu \mathrm{l}), 1.0 \mu \mathrm{l}$ of each primer $(50 \mathrm{pm} / \mu \mathrm{l})$ and $0.3 \mu \mathrm{l}$ Taq DNA polymerase (5 U/ $\mu 1$, Takara Shuzon). The amplification was performed as follows: $95^{\circ} \mathrm{C}$ for $5 \mathrm{~min}$ followed by 32 cycles of $94^{\circ} \mathrm{C}$ for $40 \mathrm{sec}, 60^{\circ} \mathrm{C}$ for $40 \mathrm{sec}$ and $72^{\circ} \mathrm{C}$ for $60 \mathrm{sec}$, with a final extension step of $10 \mathrm{~min}$ at $72^{\circ} \mathrm{C}$. mRNA expression levels were recorded by calculating the absorbance ratio of the target gene strap and GAPDH/ $\beta$-actin strap.

Western blotting. The retinas were dissected and homogenized in lysis buffer (10 mM Tris, pH 7.4; $150 \mathrm{mM} \mathrm{NaCl}$; $1 \mathrm{mM}$ EDTA; $1 \mathrm{mM}$ EGTA) supplemented with $10 \%$ protease inhibitor cocktail and 1\% phosphatase inhibitor cocktail from Sigma (St. Louis, MO, USA). Cell debris was removed by centrifugation. The protein concentration of the supernatant was measured using a Bio-Rad DC protein assay kit (Bio-Rad, Hercules, CA, USA). A total of $40 \mu \mathrm{g}$ protein from each group was subjected to $10 \%$ SDS polyacrylamide gel electrophoresis and transferred onto polyvinylidene fluoride membranes at $50 \mathrm{~V}$ for $2 \mathrm{~h}$. The membranes were blocked with 5\% non-fat dry milk and $2 \%$ bovine serum albumin in Tris-buffered saline containing $0.1 \%$ Tween-20 for $1 \mathrm{~h}$. Incubations with primary polyclonal rabiit anti-rat antibodies of HIF-1 $\alpha$, iNOS, COX-2 and caspase-9 (1:200; Wuhan Boshide Company, China) in blocking buffer were performed overnight at $4^{\circ} \mathrm{C}$. After washing, the membranes were incubated with horseradish peroxidase-conjugated secondary polyclonal anti-rabbit antibody (1:2,000; Wuhan Boshide Company, China) in blocking buffer for $1 \mathrm{~h}$ at room temperature. Bands were quantified and scanned using Floorchem V2.0 software provided by the UVI pro gel analysis system (Kodak, Rochester, NY, USA). $\beta$-actin was used as an internal control.

Statistical analysis. The results are expressed as the mean \pm standard deviation. Comparisons among groups were performed by one way-analysis of variance using SPSS 12.0 (SPSS, Inc., Chicago, IL, USA). The correlations between the mRNA expression levels of HIF-1 $\alpha$ and IOP and ERG-b, and the mRNA expression levels of iNOS, COX-2 and caspase-9 were analyzed using Pearson's correlation, Kendall's correlation and Spearman's correlation. The correlation analysis of protein expression levels of HIF-1 $\alpha$ with iNOS, COX-2 and caspase- 9 was also performed using these three methods.

\section{Results}

Induction of experimental glaucoma. Cauterization of the major episcleral vein trunks resulted in increased IOP as 
Table I. Sequences of PCR primers and product length of genes.

\begin{tabular}{llc}
\hline Gene & \multicolumn{1}{c}{ Sequence (5'-3') } & Product length (bp) \\
\hline F- $\beta$-actin & ACACTGTGCCCATCTACGAGG & 621 \\
R- $\beta$-actin & AGGGGCCGGACTCGTCATACT \\
F-GAPDH & ACCACAGTCCATGCCATCAC \\
R-GAPDH & TCCACCACCCCTGTTGCTGTA \\
F-COX-2 & GCAAATCCTTGCTGTTCCAACCCA \\
R-COX-2 & TTGGGGATCCGGGATGAACTCTCT \\
F-caspase- 9 & TTTAAGCTCTCAGAAGACATG \\
R-caspase- 9 & TGTTGAAGTACAGACAGTACCCCCA \\
F-iNOS & TCCAGGAGGACATGCAGCAC \\
R-iNOS & TCTTGACGCCTTCCCGC \\
F-HIF- $1 \alpha$ & CTGATTGCATCTCCACCTTCTACC \\
R-HIF- $\alpha$ & TTCCAAGAAAGCGACATAGTAGGG & 363 \\
\hline
\end{tabular}

GAPDH, glyceraldehyde-3-phosphate dehydrogenase; COX-2, cyclooxygenase-2; iNOS, inducible nitric oxide synthase; HIF-1 $\alpha$, hypoxia-inducible factor- $1 \alpha$.

Table II. Intraocular pressure of eyes in experimental and control eyes preoperatively and at various times postoperatively.

\begin{tabular}{lcc}
\hline & $\begin{array}{c}\text { Experimental } \\
(\mathrm{n}=120, \mathrm{mmHg})\end{array}$ & $\begin{array}{c}\text { Control } \\
\text { Time }\end{array}$ \\
\hline 0 days & $12.767 \pm 3.176$ & $\mathrm{mmH})$ \\
$0.5 \mathrm{~h}$ & $30.166 \pm 6.029^{\mathrm{b}}$ & $12.846 \pm 2.769$ \\
3 days & $22.718 \pm 4.131^{\mathrm{a}}$ & $12.517 \pm 2.429$ \\
7 days & $33.942 \pm 9.208^{\mathrm{b}}$ & $12.233 \pm 3.711$ \\
14 days & $32.557 \pm 7.937^{\mathrm{b}}$ & $13.466 \pm 2.270$ \\
21 days & $25.395 \pm 2.703^{\mathrm{b}}$ & $12.825 \pm 2.791$ \\
28 days & $26.000 \pm 3.978^{\mathrm{b}}$ & $12.634 \pm 3.109$ \\
\hline
\end{tabular}

${ }^{\mathrm{a}} \mathrm{P}<0.05$ and ${ }^{\mathrm{b}} \mathrm{P}<0.01$, vs. controls.

Table III. Electroretinogram b-wave in retina following EPO injection.

\begin{tabular}{lccr}
\hline Time (days) & EVC group & EVC+EPO group & P-value \\
\hline 0 & $113.05 \pm 9.53$ & $119.45 \pm 11.43$ & 0.480 \\
3 & $92.71 \pm 7.38$ & $97.34 \pm 8.45$ & 0.430 \\
7 & $72.37 \pm 8.15$ & $98.21 \pm 10.23^{\mathrm{a}}$ & 0.025 \\
14 & $65.51 \pm 0.042$ & $95.57 \pm 9.29^{\mathrm{b}}$ & 0.009 \\
21 & $68.65 \pm 0.059$ & $93.32 \pm 6.42^{\mathrm{a}}$ & 0.016 \\
28 & $69.91 \pm 0.037$ & $95.32 \pm 9.12^{\mathrm{a}}$ & 0.038
\end{tabular}

${ }^{\mathrm{a}} \mathrm{P}<0.05$ and ${ }^{\mathrm{b}} \mathrm{P}<0.01$, vs. EVC group. EPO, erythropoietin; EVC, episcleral vein cauterization.

aqueous outflow was interrupted (Table II). There was no significant difference in IOP between the experimental and control eyes of the 120 rats prior to the EVC procedure ( 0 days; $\mathrm{P}>0.05$; Table II). At $0.5 \mathrm{~h}$ after the EVC procedure, the IOP of the experimental eyes was increased to $30.166 \pm 6.029 \mathrm{mmHg}$, which was significantly higher than that of the control eyes $(\mathrm{P}<0.01)$. The peak IOP $(33.942 \pm 9.208 \mathrm{mmHg})$ was obtained 7 days after the EVC procedure, which was 2.66 -fold higher than that at 0 days. The IOP of the experimental eyes 14, 21 and 28 days after surgery remained significantly 
Table IV. mRNA expression level of HIF-1 $\alpha$, iNOS, COX-2 and caspase-9 in retinas following EPO injection.

\begin{tabular}{|c|c|c|c|c|}
\hline Gene & Time (days) & EVC group $(\mu \mathrm{V})$ & EVC+EPO group $(\mu \mathrm{V})$ & P-value \\
\hline \multirow[t]{6}{*}{$\mathrm{HIF}-1 \alpha$} & 0 & $0.248 \pm 0.087$ & $0.234 \pm 0.072$ & 0.790 \\
\hline & 3 & $0.408 \pm 0.029$ & $0.240 \pm 0.027^{\mathrm{a}}$ & 0.020 \\
\hline & 7 & $0.512 \pm 0.028$ & $0.288 \pm 0.031^{\mathrm{b}}$ & 0.000 \\
\hline & 14 & $0.406 \pm 0.032$ & $0.312 \pm 0.026^{\mathrm{a}}$ & 0.010 \\
\hline & 21 & $0.342 \pm 0.044$ & $0.226 \pm 0.027^{\mathrm{a}}$ & 0.015 \\
\hline & 28 & $0.338 \pm 0.026$ & $0.240 \pm 0.020^{\mathrm{a}}$ & 0.030 \\
\hline \multirow[t]{6}{*}{ iNOS } & 0 & $0.259 \pm 0.053$ & $0.284 \pm 0.037$ & 0.480 \\
\hline & 3 & $0.423 \pm 0.085$ & $0.358 \pm 0.026$ & 0.088 \\
\hline & 7 & $0.676 \pm 0.065$ & $0.448 \pm 0.0441^{\mathrm{b}}$ & 0.005 \\
\hline & 14 & $0.526 \pm 0.042$ & $0.376 \pm 0.029^{\mathrm{b}}$ & 0.001 \\
\hline & 21 & $0.414 \pm 0.059$ & $0.336 \pm 0.032^{\mathrm{a}}$ & 0.036 \\
\hline & 28 & $0.394 \pm 0.037$ & $0.328 \pm 0.026^{\mathrm{a}}$ & 0.037 \\
\hline \multirow[t]{6}{*}{ COX-2 } & 0 & $0.218 \pm 0.037$ & $0.202 \pm 0.031$ & 0.317 \\
\hline & 3 & $0.392 \pm 0.033$ & $0.380 \pm 0.022$ & 0.550 \\
\hline & 7 & $0.622 \pm 0.048$ & $0.388 \pm 0.029^{b}$ & 0.001 \\
\hline & 14 & $0.552 \pm 0.043$ & $0.402 \pm 0.033^{\mathrm{a}}$ & 0.010 \\
\hline & 21 & $0.438 \pm 0.038$ & $0.374 \pm 0.029^{\mathrm{a}}$ & 0.014 \\
\hline & 28 & $0.458 \pm 0.031$ & $0.312 \pm 0.032^{b}$ & 0.000 \\
\hline \multirow[t]{6}{*}{ Caspase-9 } & 0 & $0.146 \pm 0.044$ & $0.154 \pm 0.033$ & 0.640 \\
\hline & 3 & $0.350 \pm 0.042$ & $0.240 \pm 0.032^{\mathrm{a}}$ & 0.018 \\
\hline & 7 & $0.530 \pm 0.063$ & $0.348 \pm 0.031^{\mathrm{b}}$ & 0.009 \\
\hline & 14 & $0.696 \pm 0.045$ & $0.232 \pm 0.027^{\mathrm{b}}$ & 0.000 \\
\hline & 21 & $0.390 \pm 0.037$ & $0.252 \pm 0.024^{\mathrm{b}}$ & 0.002 \\
\hline & 28 & $0.412 \pm 0.043$ & $0.300 \pm 0.043^{\mathrm{a}}$ & 0.032 \\
\hline
\end{tabular}

${ }^{\mathrm{a}} \mathrm{P}<0.05$ and ${ }^{\mathrm{b}} \mathrm{P}<0.01$, vs. EVC group. HIF-1 $\alpha$, hypoxia-inducible factor-1 $\alpha$; iNOS, inducible nitric oxide synthase; COX-2, cyclooxygenase-2; EPO, erythropoietin; EVC, episcleral vein cauterization.
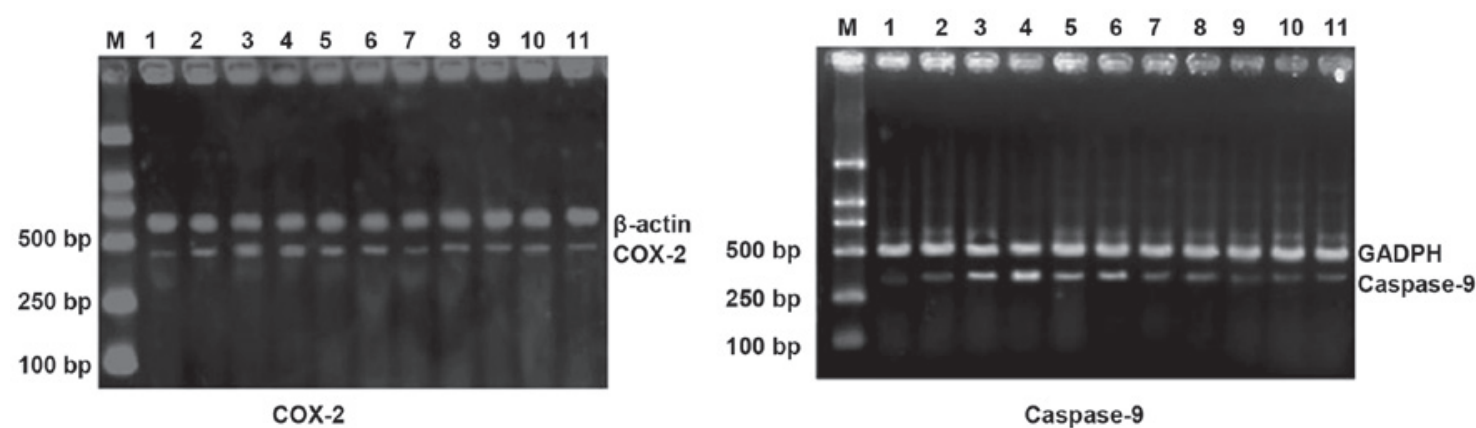

Figure 1. mRNA expression levels of HIF-1 $\alpha$, iNOS, COX-2 and caspase-9 in experimental glaucoma rats. Lane 1, control; lane 2, 3 days after EVC treatment; lane 3, 7 days after EVC treatment; lane 4, 14 days after EVC treatment; lane 5, 21 days after EVC treatment; lane 6, 28 days after EVC treatment; lane 7,3 days after EVC and EPO treatment; lane 8, 7 days after EVC and EPO treatment; lane 9, 14 days after EVC and EPO treatment; lane 10,21 days after EVC and EPO treatment; lane 11, 28 days after EVC and EPO treatment; lane M, DNA marker. HIF-1 $\alpha$, hypoxia-inducible factor-1 $\alpha$; iNOS, inducible nitric oxide synthase; COX-2, cyclooxygenase-2; EVC, episcleral vein cauterization; EPO, erythropoietin.

increased, at $>40 \%$ of that of the control eyes $(\mathrm{P}<0.01)$. The ERG-b level of the EVC+EPO group was significantly higher than that of the EVC group 7, 14, 21 and 28 days after surgery $(\mathrm{P}<0.05$, Table III).

mRNA expression levels of HIF-1 $\alpha$, iNOS, COX-2 and caspase-9. The mRNA expression levels of HIF-1 $\alpha$, iNOS,
COX-2 and caspase-9 in normal, EVC-treated, and EVC and EPO-treated rat retinas were investigated (Table IV and Fig. 1). Compared with the preoperative rats ( 0 days), the mRNA expression levels of HIF-1 $\alpha$, iNOS, COX-2 and caspase-9 in EVC-treated rats were increased. The peak expression levels of HIF-1 $\alpha$, iNOS, COX-2 and caspase-9 respectively occurred 7, 7, 7 and 14 days after surgery. Compared with 
Table V. Protein expression levels of HIF-1 $\alpha$, iNOS, COX-2 and caspase-9 in retinas following EPO injection.

\begin{tabular}{|c|c|c|c|c|}
\hline Gene & Time (days) & EVC group & $\mathrm{EVC}+\mathrm{EPO}$ group & P-value \\
\hline \multirow[t]{6}{*}{ HIF- $1 \alpha$} & 0 & $0.084 \pm 0.021$ & $0.118 \pm 0.019$ & 0.058 \\
\hline & 3 & $0.210 \pm 0.026$ & $0.164 \pm 0.011^{\mathrm{a}}$ & 0.045 \\
\hline & 7 & $0.624 \pm 0.029$ & $0.262 \pm 0.019^{\mathrm{b}}$ & 0.000 \\
\hline & 14 & $0.456 \pm 0.032$ & $0.216 \pm 0.019^{\mathrm{b}}$ & 0.000 \\
\hline & 21 & $0.274 \pm 0.027$ & $0.214 \pm 0.027^{\mathrm{b}}$ & 0.009 \\
\hline & 28 & $0.242 \pm 0.019$ & $0.176 \pm 0.017^{b}$ & 0.005 \\
\hline \multirow[t]{6}{*}{ iNOS } & 0 & $0.264 \pm 0.037$ & $0.228 \pm 0.029$ & 0.0125 \\
\hline & 3 & $0.436 \pm 0.034$ & $0.404 \pm 0.019$ & 0.210 \\
\hline & 7 & $0.860 \pm 0.050$ & $0.472 \pm 0.038^{\mathrm{b}}$ & 0.000 \\
\hline & 14 & $0.792 \pm 0.063$ & $0.414 \pm 0.029^{\mathrm{b}}$ & 0.000 \\
\hline & 21 & $0.528 \pm 0.032$ & $0.370 \pm 0.027^{\mathrm{b}}$ & 0.000 \\
\hline & 28 & $0.378 \pm 0.026$ & $0.320 \pm 0.026^{\mathrm{a}}$ & 0.011 \\
\hline \multirow[t]{6}{*}{ COX-2 } & 0 & $0.108 \pm 0.024$ & $0.096 \pm 0.018$ & 0.470 \\
\hline & 3 & $0.188 \pm 0.019$ & $0.146 \pm 0.032$ & 0.058 \\
\hline & 7 & $0.462 \pm 0.036$ & $0.274 \pm 0.021^{\mathrm{b}}$ & 0.000 \\
\hline & 14 & $0.374 \pm 0.024$ & $0.252 \pm 0.028^{\mathrm{b}}$ & 0.001 \\
\hline & 21 & $0.324 \pm 0.021$ & $0.206 \pm 0.021^{\mathrm{b}}$ & 0.000 \\
\hline & 28 & $0.340 \pm 0.027$ & $0.188 \pm 0.038^{\mathrm{b}}$ & 0.002 \\
\hline \multirow[t]{6}{*}{ Caspase-9 } & 0 & $0.184 \pm 0.031$ & $0.172 \pm 0.029$ & 0.640 \\
\hline & 3 & $0.222 \pm 0.026$ & $0.180 \pm 0.022$ & 0.055 \\
\hline & 7 & $0.376 \pm 0.021$ & $0.252 \pm 0.026^{\mathrm{b}}$ & 0.003 \\
\hline & 14 & $0.552 \pm 0.044$ & $0.280 \pm 0.040^{\mathrm{b}}$ & 0.000 \\
\hline & 21 & $0.318 \pm 0.041$ & $0.216 \pm 0.031^{\mathrm{a}}$ & 0.031 \\
\hline & 28 & $0.306 \pm 0.021$ & $0.224 \pm 0.027^{\mathrm{a}}$ & 0.012 \\
\hline
\end{tabular}

${ }^{\mathrm{a}} \mathrm{P}<0.05$ and ${ }^{\mathrm{b}} \mathrm{P}<0.01$, vs. EVC group. HIF-1 $\alpha$, hypoxia-inducible factor-1 $\alpha$; iNOS, inducible nitric oxide synthase; COX-2, cyclooxygenase-2; EPO, erythropoietin; EVC, episcleral vein cauterization.

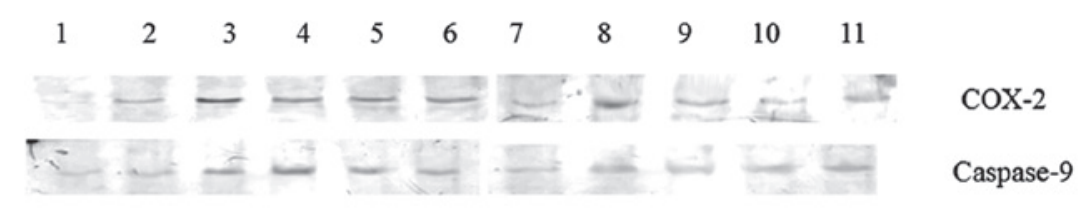

Figure 2. Protein expression levels of COX-2 and caspase-9 in experimental glaucoma rats. Lane 1, control; lane 2, 3 days after EVC treatment; lane 3, 7 days after EVC treatment; lane 4, 14 days after EVC treatment; lane 5, 21 days after EVC treatment; lane 6, 28 days after EVC treatment; lane 7, 3 days after EVC and EPO treatment; lane 8, 7 days after EVC and EPO treatment; lane 9, 14 days after EVC and EPO treatment; lane 10, 21 days after EVC and EPO treatment; lane 11, 28 days after EVC and EPO treatment; lane M, DNA marker. COX-2, cyclooxygenase-2; EVC, episcleral vein cauterization; EPO, erythropoietin.

the EVC-treated rats, the mRNA expression levels of HIF-1 $\alpha$, iNOS, COX-2 and caspase-9 in the EPO-treated group were statistically significantly reduced 7, 14, 21 and 28 days after surgery $(\mathrm{P}<0.01$, Table IV).

Protein expression levels of HIF-1 $\alpha$, iNOS, COX-2 and caspase-9. The protein expression levels of HIF-1 $\alpha$, iNOS, COX-2 and caspase-9 in normal, EVC-treated, and EVC and EPO-treated rat retinas were also investigated (Table $\mathrm{V}$ and Fig. 2). Similarly to mRNA expression levels, the protein expression levels of HIF-1 $\alpha$, iNOS, COX-2 and caspase-9 in EVC-treated rats were increased compared with those of preoperative rats. The peak expression of HIF-1 $\alpha$, iNOS,
COX-2 and caspase-9 respectively occurred 7, 7, 7 and 14 days after surgery. Compared with EVC-treated rats, the protein expression levels of HIF-1 $\alpha$, iNOS, COX-2 and caspase-9 in the EPO-treated group were notably reduced 7, 14, 21 and 28 days after surgery $(\mathrm{P}<0.01$, Table $\mathrm{V})$.

Correlation analysis. Pearson's correlation, Kendall's correlation and Spearman's correlation were used for correlation analysis. HIF-1 $\alpha$ was positively correlated with iNOS, COX-2 and caspase-9 at the mRNA level (Table VI) and protein level (Table VII). Moreover, the mRNA expression level of HIF-1 $\alpha$ also demonstrated a significant positive correlation with IOP and ERG-b (Table VI). 
Table VI. Correlation analysis of mRNA expression level of HIF-1 $\alpha$ with IOP,ERG-b and mRNAexpression levels of iNOS, COX-2 and caspase-9 in chronic ocular hypertension rats.

\begin{tabular}{lccc}
\hline & Pearson's correlation & Kendall's correlation & Spearman's correlation \\
\hline IOP & $0.751^{\mathrm{b}}$ & $0.476^{\mathrm{a}}$ & $0.598^{\mathrm{a}}$ \\
ERG-b & $0.594^{\mathrm{b}}$ & $0.397^{\mathrm{a}}$ & $0.482^{\mathrm{a}}$ \\
iNOS & $0.821^{\mathrm{b}}$ & $0.572^{\mathrm{b}}$ & $0.733^{\mathrm{b}}$ \\
COX-2 & $0.791^{\mathrm{b}}$ & $0.518^{\mathrm{a}}$ & $0.672^{\mathrm{b}}$ \\
Caspase-9 & $0.599^{\mathrm{b}}$ & $0.345^{\mathrm{a}}$ & $0.516^{\mathrm{b}}$ \\
\hline
\end{tabular}

${ }^{\mathrm{a}} \mathrm{P}<0.05$ and ${ }^{\mathrm{b}} \mathrm{P}<0.01$. HIF-1 $\alpha$, hypoxia-inducible factor- $1 \alpha$; IOP, intraocular pressure; ERG-b, electroretinogram b-wave; iNOS, inducible nitric oxide synthase; COX-2, cyclooxygenase-2.

Table VII. Correlation analysis of protein expression levels of HIF-1 $\alpha$ with iNOS, COX-2 and caspase-9 in chronic ocular hypertension rats.

\begin{tabular}{lccc}
\hline & Pearson's correlation & Kendall's correlation & Spearman's correlation \\
\hline iNOS & $0.950^{\mathrm{b}}$ & $0.726^{\mathrm{b}}$ & $0.901^{\mathrm{b}}$ \\
COX-2 & $0.882^{\mathrm{b}}$ & $0.765^{\mathrm{b}}$ & $0.908^{\mathrm{b}}$ \\
Caspase-9 & $0.715^{\mathrm{b}}$ & $0.705^{\mathrm{a}}$ & $0.881^{\mathrm{b}}$ \\
\hline
\end{tabular}

${ }^{\mathrm{a}} \mathrm{P}<0.05$ and ${ }^{\mathrm{b}} \mathrm{P}<0.01$. HIF- $1 \alpha$ hypoxia-inducible factor- $1 \alpha$; iNOS, inducible nitric oxide synthase; COX-2, cyclooxygenase- 2 .

\section{Discussion}

Glaucoma is the second leading cause of blindness worldwide (17). It is imperative to explore the mechanisms of retinal damage in glaucoma. In the present study, EVC was used for the construction of chronic ocular hypertension rats. The mRNA and protein expression levels of HIF-1 $\alpha$, iNOS, COX-2 and caspase-9 were investigated in chronic ocular hypertension rats. Moreover, a correlation analysis of HIF-1 $\alpha$ with IOP, ERG-b, iNOS, COX-2 and caspase-9 was also conducted.

First, an inducible rat model of elevated IOP was developed using the EVC method. Following cauterization of two episcleral veins in the rats, IOP increases of $50-80 \%$ were reported in treated eyes, with a loss of $4 \%$ of the retinal ganglion cells per week (18). Cauterization of three episcleral veins produced an IOP increase of $120-150 \%$, with a loss of $5-6 \%$ of retinal ganglion cells per week (19). Two or three of the major episcleral veins were coagulated in the experimental group of the present study. The peak IOP (33.942 \pm 9.208 , $\mathrm{P}<0.01$ ) was obtained 7 days after the EVC procedure, and was 2.66-fold higher than that at 0 days. This result was in accordance with previous studies $(18,19)$.

The mRNA expression levels of HIF-1 $\alpha$, iNOS, COX-2 and caspase-9 in EVC-treated rats were increased significantly compared with those in normal rats. The peak expression levels of HIF-1 $\alpha$, iNOS, COX-2 and caspase-9 were obtained 7, 7, 7 and 14 days after surgery. The correlation analysis indicated that HIF-1 $\alpha$ had a significant positive correlation with iNOS, COX-2 and caspase-9 at both the mRNA and protein level. Moreover, HIF-1 $\alpha$ also demonstrated a significant positive correlation with IOP and ERG-b.
COX-2 is an inducible enzyme with a significant role in inflammation. It is overexpressed in a variety of cancer types and plays an essential role in the angiogenesis of gastric carcinoma $(20,21)$. A previous study indicated that COX-2 is transcriptionally induced by hypoxia via HIF-1, and the upregulation of COX-2 contributes to maintaining tumor survival and potentially promoting angiogenesis in colorectal tumor cells (22). Lukiw et al reported coordinated activation of HIF-1 and COX-2 expression in retinal cells by hypoxia (12). Caspase-9 is the apex caspase of the mitochondrial pathway of apoptosis, which plays a critical role in apoptotic initiation and progression (14). Hänninen et al investigated retinal ganglion cell death and activation of caspase-9 in rats with experimental glaucoma and supported the activation of caspase- 9 , the intrinsic caspase cascade, in retinal ganglion cell death in experimental glaucoma (15). The upregulated caspase- 9 in experimental glaucoma may result in retinal ganglion cell death and aggravate the development of glaucoma. These studies further support the results revealed in the present study. Thus, COX-2 and caspase-9 overexpression may be regarded as a critical adaptive response to hypoxia in glaucoma. Several studies have examined the observation that HIF-1 $\alpha$ immunoreactivity is enhanced in the glaucomatous retina in a canine glaucoma model and in human glaucoma $(4,6,9,23)$. Upon activation by hypoxia and/or receptor-mediated signals, the HIF-1 $\alpha$ expression level was increased and several HIF-1 transcriptional targets were upregulated in the glaucomatous retina in the present study and our previous study (9). Moreover, significant positive correlations with HIF-1 $\alpha$, iNOS, COX-2, caspase-9, IOP and ERG-b were identified in the current study. It furthermore indicates the significant role of HIF-1 $\alpha$ in the development and progression of glaucoma. 
Compared with EVC-treated rats, EPO administration weakened the mRNA and protein expression levels of HIF-1 $\alpha$, iNOS, COX-2 and caspase-9. Glaucoma is characterized by the progressive death of retinal ganglion cells and visual field loss. EPO has been reported to provide neuroprotection in cultured adult rat retinal ganglion cells, with anti-oxidative, anti-apoptotic and neurotrophic effects observed in several signaling pathways $(24,25)$. The neuroprotection of EPO in retinal ganglion cells may be a potential reason for the downregulated expression levels of HIF-1 $\alpha$, iNOS, COX-2 and caspase-9 in experimental glaucoma rats.

In conclusion, the mRNA and protein expression levels of HIF-1 $\alpha$, iNOS, COX-2 and caspase-9 were investigated in EVC-treated chronic ocular hypertension rats, and the correlation of HIF-1 $\alpha$ with IOP, ERG-b, iNOS, COX-2 and caspase-9 was also studied. Upregulated levels of HIF-1 $\alpha$, iNOS, COX-2 and caspase- 9 were observed in experimental glaucoma rats. HIF-1 $\alpha$ demonstrated a significant correlation with iNOS, COX-2, caspase-9, IOP and ERG-b. HIF-1 $\alpha$, iNOS, COX-2 and caspase- 9 overexpression may be regarded as a critical adaptive response to hypoxia in glaucoma. EPO administration weakened the mRNA and protein expression levels of HIF-1 $\alpha$, iNOS, COX-2 and caspase-9. To conclude, the protective effect of EPO on the retina of chronic ocular hypertension rats may be mediated by the HIF-1 signaling pathway involving iNOS, COX-2 and caspase-9.

\section{References}

1. Vohra R, Tsai JC and Kolko M: The role of inflammation in the pathogenesis of glaucoma. Surv Ophthalmol 58: 311-320, 2013.

2. Nickells RW: Ganglion cell death in glaucoma: from mice to men. Vet Ophthalmol 10 (Suppl 1): 88-94, 2007.

3. Semenza GL: HIF-1 and mechanisms of hypoxia sensing. Curr Opin Cell Biol 13: 167-171, 2001.

4. Tezel G and Wax MB: Hypoxia-inducible factor 1 alpha in the glaucomatous retina and optic nerve head. Arch Ophthalmol 122: 1348-1356, 2004.

5. Jiang B-H,Semenza GL,Bauer C and Marti HH: Hypoxia-inducible factor 1 levels vary exponentially over a physiologically relevant range of O2 tension. Am J Physiol 271: C1172-C1180, 1996.

6. Ergorul C, Ray A, Huang W, et al: Hypoxia inducible factor-1a (HIF-1 $\alpha$ ) and some HIF-1 target genes are elevated in experimental glaucoma. J Mol Neurosci 42: 183-191, 2010.

7. Zhu Y, Zhang L and Gidday JM: Role of hypoxia-inducible factor-1alpha in preconditioning-induced protection of retinal ganglion cells in glaucoma. Mol Vis 19: 2360-2372, 2013.

8. Whitlock NA, Agarwal N, Ma J-X and Crosson CE: Hsp27 upregulation by HIF-1 signaling offers protection against retinal ischemia in rats. Invest Ophthalmol Vis Sci 46: 1092-1098, 2005.
9. Gui DM, Yang Y, Li X and Gao DW: Effect of erythropoietin on the expression of HIF-1 and iNOS in retina in chronic ocular hypertension rats. Int J Ophthalmol 4: 40-43, 2011.

10. Fu QL, Wu W, Wang H, Li X, Lee VW and So KF: Up-regulated endogenous erythropoietin/erythropoietin receptor system and exogenous erythropoietin rescue retinal ganglion cells after chronic ocular hypertension. Cell Mol Neurobiol 28: 317-329, 2008.

11. Yanni SE, McCollum GW and Penn JS: Genetic deletion of COX-2 diminishes VEGF production in mouse retinal Müller cells. Exp Eye Res 91: 34-41, 2010.

12. Lukiw WJ, Ottlecz A, Lambrou G, et al: Coordinate activation of HIF-1 and NF- $\kappa$ B DNA binding and COX-2 and VEGF expression in retinal cells by hypoxia. Invest Ophthalmol Vis Sci 44: 4163-4170, 2003.

13. Soengas MS, Alarcón RM, Yoshida H, Giaccia H, Hakem R, Mak TW and Lowe SW: Apaf-1 and caspase-9 in p53-dependent apoptosis and tumor inhibition. Science 284: 156-159, 1999.

14. Nishiyama J, Yi X, Venkatachalam M and Dong Z: cDNA cloning and promoter analysis of rat caspase-9. Biochem J 360: 49-56, 2001.

15. Hänninen VA, Pantcheva MB, Freeman EE, Poulin NR and Grosskreutz CL: Activation of caspase 9 in a rat model of experimental glaucoma. Curr Eye Res 25: 389-395, 2002.

16. Goldblum D and Mittag T: Prospects for relevant glaucoma models with retinal ganglion cell damage in the rodent eye. Vision Res 42: 471-478, 2002.

17. Quigley HA and Broman AT: The number of people with glaucoma worldwide in 2010 and 2020. Br J Ophthalmol 90: 262-267, 2006

18. Laquis S, Chaudhary P and Sharma SC: The patterns of retinal ganglion cell death in hypertensive eyes. Brain Res 784: 100-104, 1998.

19. Ahmed FA, Chaudhary P and Sharma SC: Effects of increased intraocular pressure on rat retinal ganglion cells. Int J Dev Neurosci 19: 209-218, 2001.

20. Huang SP, Wu MS, Shun CT, et al: Cyclooxygenase-2 increases hypoxia-inducible factor-1 and vascular endothelial growth factor to promote angiogenesis in gastric carcinoma. J Biomed Sci 12: 229-241, 2005.

21. Wang D and Dubois RN: The role of COX-2 in intestinal inflammation and colorectal cancer. Oncogene 29: 781-788, 2010.

22. Kaidi A, Qualtrough D, Williams AC and Paraskeva C: Direct transcriptional up-regulation of cyclooxygenase- 2 by hypoxia-inducible factor (HIF)-1 promotes colorectal tumor cell survival and enhances HIF-1 transcriptional activity during hypoxia. Cancer Res 66: 6683-6691, 2006.

23. Savagian CA, Dubielzig RR and Nork TM: Comparison of the distribution of glial fibrillary acidic protein, heat shock protein 60 , and hypoxia-inducible factor- $1 \alpha$ in retinas from glaucomatous and normal canine eyes. Am J Vet Res 69: 265-272, 2008.

24. Chang ZY, Yeh MK, Chiang $\mathrm{CH}$, Chen $\mathrm{YH}$ and Lu DW: Erythropoietin protects adult retinal ganglion cells against NMDA-, trophic factor withdrawal-, and TNF- $\alpha$-induced damage. PLoS One 8: e55291, 2013.

25. Zhong L, Bradley J, Schubert W, et al: Erythropoietin promotes survival of retinal ganglion cells in DBA/2J glaucoma mice. Invest Ophthalmol Vis Sci 48: 1212-1218, 2007. 